\title{
Relationship between Person-Organization Fit and Performance Indices of Public Hospitals Affiliated with Qazvin University of Medical Sciences in Iran
}

\author{
Zahra Taghvaei-Keshtkar ${ }^{1}$, Leila Riahi ${ }^{1, *}$ \\ ${ }^{I}$ Department of Health Services Management, Science and Research Branch, Islamic Azad University (IAU), Tehran, IR Iran
}

*Corresponding Author: Leila Riahi, Assistant Professor of Health Services Management, Department of Health Services Management, Science and Research Branch, Islamic Azad University (IAU), Tehran, Iran. Tel:098-9121131901; Email: 1.riahi@srbiau.ac.ir

Received: 4 Nov. 2015; Accepted: 28 Jan. 2016; Online Published: 28 May. 2016

\begin{abstract}
Background: Person-organization fit is an effective factor for recruiting, selection, and retention of human resources in organizations.

Objective: This study examined the correlation between person-organization fit and performance indicators used in healthcare in the hospitals affiliated with Qazvin University of Medical Sciences (QUMS).

Methods: This descriptive cross-sectional study was conducted in 2014. A total of 324 employees were randomly selected from among the study population comprising the staff of teaching hospitals affiliated with QUMS. The sample size was distributed between the hospitals using the class-ratio method. Data were collected using person-organization fit (Scroggins) questionnaires, and their validity and reliability were evaluated. Data analysis was done using Spearman-Pearson correlation, chi-square, and Kruskal-Wallis tests.

Results: In terms of values fit, personality fit, and skills, knowledge, and ability fit, hospital C ranked first among the hospitals tested with average ratings of 175.99, 195.53, 199.49, respectively. Significant relationships were found between person-organization fit and patients admitted per bed, median duration of patient stay, and crude mortality rate. No significant relationships were found between personorganization fit and the performance indicators of bed circulation and bed occupancy rate $(\mathrm{p} \leq 0.05)$.

Conclusion: In order to show an association between person-organization fit and the performance indicators, more efficient use of resources and improved efficiency is suggested. Policymakers must pay more attention to person-organization fit during recruitment, selection, and assignment of staff.
\end{abstract}

Keywords: Person-Organization Fit, Performance Indicators, Hospitals

\section{Background}

Employees are the most valuable assets of an organization. In the service industry, such as organizations offering medical and health services, these assets are twice as valuable [1]. Recent studies on business strategies show that a competitive advantage could be gained by organizations by concentrating on human resources as the most important strategic resources. Human resources are intangible assets that create value for the organization by increasing its ability to face a competitive environment [2].

If an organization neglects its human resources and fails to train and guide them properly, it will not be possible to fully use their abilities [3]. Human capital, in contrast to physical capital are less predictable because of their understanding, attitudes, and personalities differ [4]. Most organizations seek individuals who respond best to job requirements, are more compatible with job training and changes, and are committed to the organization. Individuals look for organizations that are able to use their expertise and satisfy their specific needs [4].

The goals of an organization can be fulfilled when individuals respect the values of an organization and strive toward its main goals. This will not occur unless the organization respects the goals and personal values of their employees, meet their needs, responds to their requests, and presents a job description that meets their personality specifications, interests and desires. This personorganization fit is one of the most important variants in the work environment of an organization and has been a focus of attention for researchers and employees in recent years $[5]$.

Person-organization fit is the compatibility pattern of organizational values with individual values [6]. Kristoff (quoting from Levin) believes that person-organization fits as "compatibility between individuals and organizations at workplaces" [7]. Theory and research have shown that five factors can be used to measure the degree of personorganizational fit when studying the relationship with behavioral consequences of compatibility of values, goals, personal, work environment, and knowledge, skill, and ability (KSA) [8]. Person-organization fit theory states there are features in an organization that are compatible with individual features and specifications and indicates that individual behaviors and attitudes are affected by the degree of compatibility, or fit, existing between individuals and organizations [9]. The attitudes include satisfaction, success in an equivalent job, and the desire to stay with the organization, work behavior including job performance and organizational citizenship [10].

The fit between an individual and organization is an effective factor used to determine why individuals are attracted to certain organizations, chosen by an organization, and stay with an organization [6, 7]. Researcher interest in this area stems from the ability to predict work results by means of person-organization fit [6, 11]. One standard by which to measure performance of a hospital and determine the level of achievement of desired goals is to use hospital statistics and indices [12, 13]. 
Improvement of hospital indices can increase the efficiency and effectiveness of hospital operation as exemplified by effective employee performance and use of resources [14].

\section{Objective}

A relationship between person-organization fit and hospital performance indices could affect factors including the quality of service, profitability, consumer satisfaction, the beneficiaries of the organization, and societal health. Offering services is only possible by means of a professional work force. The current study examined the relationship between person-organization fit and the performance indices of hospitals affiliated with Qazvin University of Medical Sciences (QUMS) to determine the type and density of the connection between these two variants for use in a real environment.

\section{Methods}

The present descriptive-correlative research was goaloriented and cross-sectional and was carried out at the public hospitals affiliated with QUMS during 2014. The study population included all employees of the hospitals examined. Sampling was done in a multi-level manner. The approximate size of the study population was determined using a Morgan table, the number of samples was determined and allocated by stratified sampling and the test subjects were then randomly selected. Eligible employees were those with more than one year of work experience at the specific hospital. The research sample size was determined to be 324 subjects (hospital A: 120, hospital B: 100, hospital C: 104). The standard for elimination of a subject was lack of response to the questionnaire after three follow-ups over the course of one week.

Data related to person-organization fit were gathered using the Scroggin person-organization fit questionnaire. This questionnaire comprises 21 questions covering five aspects of compatibility of personal values, goals, and personal, work environment, and KSA. The validity of the questionnaire was calculated as recommended by Shams et al. as being $95 \%$ and its permanency was calculated as $85 \%$ to $98 \%$ by means of the test and re-test method.

The opinions of the subjects were determined using a 6 level Likert scale (totally agree, agree, agree somewhat, disagree somewhat, disagree, totally disagree) with values from 1 to 6 , respectively, assigned to each answer. Data related to hospital performance indices were gathered using the following indices: bed occupancy coefficient, ratio of patients admitted per active bed, median duration of patient stay, circulation distance (bed performance), and raw mortality rate. These statistics were gathered from the medical records section of the hospitals. SPSS software (v. 20) and descriptive statistical indices such as percent, median, average, standard redundancy, and variance were used to analyze the data. The Kalmograph-Smirnoff test was used to study normal data. Non-parametric methods such as the K2 test were used to analyze personorganization fit. Spearman's correlation test was used to evaluate the relationship between person-organization fit and hospital performance indices.

\section{Results}

The results showed that $74 \%$ of the study sample were female and $46 \%$ were men; $69 \%$ were married and the rest were single. The largest percentage of subjects $(35 \%)$ were
22-27 years of age and the smallest percentage (1\%) were +51 years of age. Most subjects held a BS degree (71\%) and the smallest percentage held doctorate degrees (1\%). The employment condition of most subjects (33\%) was contract-based with a small percentage $(8 \%)$ had officialexperimental agreements.

Most subjects had a work history of 1-5 years (37\%) and $1 \%$ had a history of $25-29$ years. Table 1 shows that the bed occupancy coefficient at hospital A was $81 \%$, which is higher than for hospitals $\mathrm{C}(75 \%)$ and $\mathrm{B}(70 \%)$. For the ratio of patients admitted per active bed, hospital $\mathrm{B}$ ranked first over hospitals A and C. Median duration of patient stay was 3.1 days for hospital B which ranked first over hospital A with 4.42 days and $C$ with 4.5 days. The circulation distance of hospital beds was 1.2 for hospital B, 2.72 for hospital A and 2 for hospital C. Among these hospitals hospital B was ranked first in regards to the distance of hospital beds. The raw mortality rate was 117 deaths per 1000 patients for hospital $\mathrm{C}$ hospital which ranked first in comparison with hospital B at 128/1000 deaths and hospital A at 359/1000 deaths.

Table 1. Performance indices of hospital

\begin{tabular}{lccc}
\hline Hospital Performance Index & $\begin{array}{c}\text { Hospital } \\
\text { A }\end{array}$ & Hospital B & Hospital C \\
\hline Bed occupancy coefficient & $81 \%$ & $70.7 \%$ & $75 \%$ \\
Ratio of patients admitted per & 5.32 & 6.9 & 4 \\
active bed & 4.42 & 3.1 & 4.5 \\
Median duration of patient stay & 2.72 & 1.2 & 2 \\
Bed circulation distance (bed & $359 / 1000$ & $128 / 1000$ & $117 / 1000$ \\
performance) & & & \\
Raw mortality rate & & & \\
\hline
\end{tabular}

The results presented in this research indicate that personorganization fit applied to all aspects and dimensions. Table 2 shows that, of the three hospitals studied for personorganization fit, hospital $\mathrm{C}$ with an average of 189.04 ranked first and hospitals $\mathrm{B}$ and $\mathrm{A}$ ranked second and third with averages of 153.55 and 146.96 , respectively.

Table 2. Median of person-organization fit in hospitals

\begin{tabular}{lcc}
\hline Hospital & Median Level & Number of Observations \\
\hline A & 146.96 & 120 \\
B & 153.55 & 100 \\
C & 189.04 & 104 \\
\hline
\end{tabular}

Table 3 indicates that there was no significant relationship between goal fit and work environment fit and any performance index $(\mathrm{p} \geq 0.05)$. The findings show a positive significant relationship between fit of personal and organization values with ratio of patients admitted per active bed $(\mathrm{r}=0.291)$ and median duration of patient stay $(\mathrm{r}=0.281)$ and a negative inverse relationship between these two factors and raw mortality rate $(\mathrm{r}=0.189)(\mathrm{p} \geq 0.01)$. The fit of employee personality and the ratio of patients admitted per active bed $(\mathrm{r}=0.227)$ and the median duration of patients $(\mathrm{r}=0.237)$ showed positive and significant relationships and a negative inverse relationship with the raw mortality rate $(r=-0.194)(p \geq 0.01)$. A negative inverse relation existed between the fit of KSA of employees required by the organization and bed occupancy coefficient $(\mathrm{r}=-0.1444)$, circulation distance $(\mathrm{r}=-0.12)$, and raw mortality rate $(\mathrm{r}=-0.156)(\mathrm{p} \leq 0.01)$.

The findings show that there is a positive significant relationship between person- organization fit and ratio of patients admitted per active bed and median duration of stay $(r=0.152)$ and a negative inverse relationship with raw 
mortality rate $(\mathrm{r}=-0.177) \quad(\mathrm{p} \leq 0.01)$. No significant relationship was observed for person-organization fit with circulation performance or bed occupancy coefficient $(\mathrm{p} \leq 0.01)$.

Table 3. Dimensions of person-organization fit vs. hospital performance indices

\begin{tabular}{|c|c|c|c|c|c|c|}
\hline Person-Organization Fit & nce Index & $\begin{array}{l}\text { Bed Occupancy } \\
\text { Coefficient }\end{array}$ & $\begin{array}{l}\text { Raw Mortality } \\
\text { Rate }\end{array}$ & $\begin{array}{l}\text { Bed Circulation Distance } \\
\text { (Bed Performance) }\end{array}$ & $\begin{array}{c}\text { Median Duration } \\
\text { of Patient Stay }\end{array}$ & $\begin{array}{l}\text { Ratio of Patients } \\
\text { Admitted per Bed }\end{array}$ \\
\hline \multirow{2}{*}{ Value } & $\mathrm{r}$ & -0.189 & 0.069 & 0.281 & 0.291 & 0.068 \\
\hline & $\mathrm{p}$ & 0.001 & .223 & .000 & .000 & 0.225 \\
\hline \multirow{2}{*}{ Goal } & $\mathrm{r}$ & -0.103 & -0.033 & 0.078 & 0.079 & -0.031 \\
\hline & $\mathrm{P}$ & 0.065 & 0.570 & 0.150 & 0.156 & 0.574 \\
\hline \multirow{2}{*}{ Working environment } & $\mathrm{r}$ & -0.074 & -0.03 & 0.05 & 0.049 & -0.029 \\
\hline & $\mathrm{p}$ & 0.186 & 0.529 & 0.379 & 0.377 & 0.598 \\
\hline \multirow{2}{*}{ Personality } & $\mathrm{r}$ & -0.194 & 0.02 & 0.237 & 0.227 & 0.013 \\
\hline & $\mathrm{p}$ & .000 & 0.80 & .000 & .000 & 0.813 \\
\hline \multirow{2}{*}{ Knowledge, skill, and ability } & $\mathrm{r}$ & -0.156 & -0.12 & 0.016 & 0.016 & -0.144 \\
\hline & $\mathrm{p}$ & 0.005 & 0.009 & 0.771 & 0.771 & 0.007 \\
\hline \multirow{2}{*}{ Person-organization } & $\mathrm{r}$ & -0.177 & -0.039 & 0.152 & 0.152 & -0.039 \\
\hline & $\mathrm{p}$ & 0.001 & 0.481 & 0.006 & 0.006 & 0.481 \\
\hline
\end{tabular}

\section{Discussion}

The results show that the median for all dimensions of person-organization fit (values, goals, work environment, employee personality, and KSA) are at acceptable levels. Shams et al. reported a median person-organization fit in the hospitals they studied to be average [12]. Abzeri et al. reported that the person-organization fit with the properness of factors condition was acceptable after calculating the person-organization fit based on the medians of all factors (values, goals, work environment, employee personality, and KSA) which is in agreement with the results of the present study [13]. Gholipour et al. reported the organizational fit variant (median: 3.31) and its factors of values, goals, and personality (median: 3.29, 3.34, 3.78, respectively) to be satisfying and said that the fit of employees and organization was proper [4]. Tepsy \& Bartold studied 182 students of hospital administration and reported the person-organization fit to be 4.21 [15]. Raieesi et al. studied nursing managers and found job specification and manager interest to be above average and the median of SKA, personality, goals, and values to be less than average [8].

Among the hospitals studied, a considerable difference existed between person-organization fit. Velayat Hospital with a median of 189.04 ranked first, Shahid Rajaiee Hospital with a median of 153.55 ranked second, and BuAli Sina Hospital with a median of 146.96 ranked third. A significant difference was observed between the median of fitness for values, employee personality, and SKA. For fitness of goals with work environment, all three hospitals were similar and no differences were observed. It appears that the lack of a difference in the medians of these dimensions relates to the compatibility of the hospital organizational essence and structure because all three hospitals were supervised by the Qazvin University of Medicine, which put them on common ground for environment and goals, which itself effects the people in the organization.

The results show a positive and direct relationship between person-organization fit and the ratio of patients admitted per active bed and median duration of patient stay and a negative inverse relationship between values and raw mortality rate $(\mathrm{p} \leq 0.01)$. It appears that when individual values do not fit the professional values, it will lead to negative consequences $[17,16]$. Researchers have found that individuals having values compatible with organizational values have a more positive attitude toward their work [6].
There is a direct relation between the fitness of individual personality-organizational essence with the ratio of patients admitted per active bed and median duration of patient stay and an inverse relationship with raw mortality rate $(\mathrm{p} \leq$ 0.01). Verquir et al. analyzed person-organization fit and attitudes related to work found out that personal compatibility had a positive relationship with employee satisfaction and organizational commitment [18]. The current research did not observe a relationship between the fitness of employee goals, organization goals and work environment with any performance index. Abazary et al. found that the fitness of goals, values, and work environment had no relationship to the desire of a faculty member to retire [13].

Shams et al. observed a significant statistical relationship between person-organization fit and emotional, continuous, normative, and organizational commitment among all employees which improved person-organization fit and led to greater organizational commitment of employees [12]. Ardalan et al. stated that there is a direct relation between the average overall organizational culture score and personorganizational uniqueness [19]. This relation could relate to value and goal compatibility and work environment.

The results of present research showed a positive significant relationship between person-organization fit with the ratio of patients admitted per active bed and median duration of patient say and a negative inverse relationship between person-organization fit and raw mortality index $(\mathrm{p} \leq 0.01)$. Hosseini et al. reported a relationship between manager leadership style and the percentage of beds occupied, average duration of patient stay, bed turnover, and distance of bed turnover [20]. Andoras et al. found that organizational commitment is a positive consequence of person-organization fit [21]. Kalkan et al. found $n$ inversed relationship between personorganization fit and job stress and conflict [22]. The results of Lam et al. showed that person-organization fit effects positive agreement, positive performance, and citizenship behavior. Brian \& Daivid reported a direct relationship between person-organization fit and personal performance and employee desire to leave work [23].

\section{Conclusion}

It was concluded that there is a direct relation between person- organization fit and performance indices. It appears that as employee-organization fit improves, it improved the hospital performance indices. The key role played by the employees in hospital performance suggests that managers 
and authorities create and tailor educational programs and personal and organizational plans using data from evaluation of person-organization fit. The data from evaluation of person-organization fit can be used to define a job direction and the movement or replacement of employees. Organizations should possess such knowledge of their employees' organizational goals, values, and expectations and should identify their needs, values, and goals to create a basis for greater compatibility. To achieve organizational goals, improvement in individual employee performance and the efficiency and effectiveness indices will improve organizational profitability.

\section{Acknowledgements}

The help of all the educational-medical personnel at the public hospitals in the city of Qazvin is greatly appreciated.

\section{Authors' Contributions}

All authors contributed equally in the preparation of this paper.

\section{Conflict of Interest}

No conflict of interest has been declared by the authors.

\section{References}

1. Alaedini F, Mirza Sadeghi A, Karimi S, Moghari M, Maleki A, Tajik Saeedi J. Performance management system in Ziaeian hospita emergency [Online]. 2003 [cited 2010 Apr 20].

2. April Chang W-J, Chun Huang T. Relationship between strategic human resource management and firm performance: A contingency perspective. Int J Manpow. 2005;26(5):434-49. [DOI]

3. Armstrong M, Baron A. Strategic HRM: The key to improved business performance: CIPD Publishing; 2002.

4. Gholipour A, Roshannejad M, Sherafat S. Explaining the impact of person-organization fit on work alienation and work engagement. Strategic Manag Thought. 2010;4(1):209-30. Persian

5. Cable DM, Judge TA. Person-organization fit, job choice decisions, and organizational entry. Organ Behav Hum Decis Process. 1996;67(3):294-311. [DOI]

6. Chatman J, editor Matching people and organizations: Selection and socialization in public accounting firms. Academy of Management Proceedings; 1989: Academy of Management

7. Lewin K. Field Theory in Social Science, Selected Theoretica Papers, edited by D. Cartwright. D, New York, NY, Harpers. 1951.

8. Reisi A, Bahrami S, Safdari S, Shafiei S. Evaluating the relationship between individual-organization fit and job satisfaction among nursing managers in University Hospitals of Isfahan, Iran. Health
Inf Manag. 2013;9(7):1024-31. Persian

9. Billsberry J, Ambrosini V, Moss-Jones J, Marsh P. Some suggestions for mapping organizational members' sense of fit. J Bus Psychol. 2005;19(4):555-70. [DOI]

10. Hoffman BJ, Woehr DJ. A quantitative review of the relationship between person-organization fit and behavioral outcomes. J Vocat Behav. 2006;68(3):389-99. [DOI]

11. Van Hooft EA, Born MP, Taris TW, Van der Flier H. Ethnic and Gender Differences in Applicants' Decision-Making Processes: An Application of the Theory of Reasoned Action. Int J Select Assess. 2006;14(2):156-66. [DOI]

12. Ravaghi H, Shams L, Aryankhesal A, Salehi M. Personorganization fit and organizational commitment in University Hospitals of Tehran University of Medical Sciences, Iran. Health Inf Manag. 2013;10(2):281-91. Persian

13. Abzari M, Abbasi A, Haghshenas A, Ansari ME. The impact of organizational person-organization fit and organizational culture on organizational behaviors of university faculties in university.(Case study: Shahid Bahonar University of Kerman). Manage Res Iran. 2010;14(2):1-20. Persian

14. Amerioun A, Mahmoudi N. Hospital manager's leadership style from staffs viewpoint and its relationship with hospital indicators. J Mil Med. 2011;13(3):125-32.

15. Tepeci M, Bartlett AB. The hospitality industry culture profile: a measure of individual values, organizational culture, and personorganization fit as predictors of job satisfaction and behavioral intentions. Int J Hosp Manag. 2002;21(2):151-70. [DOI]

16. Kristof-Brown A, Barrick MR, Kay Stevens C. When opposites attract: a multi-sample demonstration of complementary personteam fit on extraversion. J Personal. 2005;73(4):935-58. [DOI]

17. Feldman DC, Ng TW. Careers: Mobility, embeddedness, and success. J Manag. 2007;33(3):350-77. [DOI]

18. Verquer ML, Beehr TA, Wagner SH. A meta-analysis of relations between person-organization fit and work attitudes. J Vocat Behav. 2003;63(3):473-89. [DOI]

19. Ardalan MR, Salimi Q, Rajaeepour S, Molavy H. A study of Relationship between Person-Organization Fit and Organizational Culture in Western Iran State Universities) Hamedan, Kermanshah and Kordestan). Q J Res Plan High Edu. 2008;14(1):97-131.

20. Amerioun A, Hosseini Shokouh J, Zaboli R, Karimi Zarchi A. Management style of military hospitals and its relationship with hospital performance indicators. J Mil Med. 2013;15(1):59-68.

21. Van Vianen AE, Shen CT, Chuang A. Person-organization and person-supervisor fits: Employee commitments in a Chinese context. J Organ Behav. 2011;32(6):906-26. [DOI]

22. Ulutas M, Kalkan A, Bozkurt ÖC. The effect of person-organization fit on job stress and conflict: An application on employees of businesses in Dalaman international airport. Int J Social Sci Hum Studies. 2008;3(1):281-91.

23. Gregory BT, Albritton MD, Osmonbekov T. The mediating role of psychological empowerment on the relationships between $\mathrm{P}-\mathrm{O}$ fit, job satisfaction, and in-role performance. $\mathrm{J}$ Bus Psychol. 2010;25(4):639-47.[DOI] 